\title{
POSSIBILIDADES DE REPRESENTAÇÕES DO LUGAR: MEDIAÇÕES PEDAGÓGICAS RUMO À CARTOGRAFIAS ALTERNATIVAS EM FEIRA DE SANTANA -BA
}

\author{
JAQUELINE DE JESUS DE LEMOS 1 \\ 1. Bolsista PEVIC-UEFS, Graduanda de Licenciatura em Geografia, Universidade Estadual de Feira de Santana, email: \\ jake-llyne@hotmail.com \\ CLÉA CARDOSO DA ROCHA ${ }^{2}$ \\ 2. Orientadora, Departamento de Educação, Universidade Estadual de Feira de Santana, e-mail: cleabase@ yahoo.com.br
}

\section{PALAVRAS-CHAVE: CARTOGRAFIAS ALTERNATIVAS; ENSINO DE GEOGRAFIA; LUGAR.}

\section{INTRODUÇÃOO}

A representação espacial sempre foi um dos objetivos da geografia, sendo a cartografia considerada um método preciso de representar a realidade baseado em cálculos matemáticos complexos que via de regra seriam acessíveis apenas para poucos iluminados. No entanto, Seemann (2012) nos alerta que atrás dos pontos, linhas e polígonos impressos no papel escondem-se homens (e mulheres) e suas razões, ações e contradições cartográficas que influenciam ou até determinam como devem ser a aparência e os conteúdos de um mapa. Tradicionalmente, o estudo da cartografia tem sido um dos principais entraves no ensinoaprendizagem de geografia, identificados tanto por professores quanto educandos dos níveis fundamental e médio. Girardi (2009), afirma que o estatuto imagético dos mapas, seu poder de fixação documental dos atributos de um pedaço de mundo do qual a Geografia fala, transformao em legitimador do fazer geográfico, transferindo sua força de símbolo também para o ensino de Geografia.

Dessa maneira, faz-se necessário ir além dos chamados elementos básicos dos mapas, ir além das medidas, coordenadas e objetos para cartografar lugares e incluir contextos e significados na folha de papel (SEEMANN, 2012). A partir destas reflexões levanta-se os seguintes questionamentos: Quais são as relações entre mapas e lugar? De que maneira podemos mapear lugares cartograficamente? Como mapas podem auxiliar à construção do conceito de lugar? Quais as relações existentes entre os mapas oficiais de Feira de Santana e os mapas desenhados por alunos do ensino fundamental e médio de geografia? Como podemos problematizar o trabalho das representações espaciais relacionando lugar, obras de arte e cartografia? De que maneira a produção desses mapas podem melhorar a aprendizagem de geografia? $\mathrm{Na}$ tentativa de responder às estas questões, foi desenvolvida uma pesquisa/intervenção, no âmbito da escola básica, objetivando a análise da produção de mapas/representações expressando o sentido do lugar, por alunos do ensino médio.

\section{MATERIAIS E MÉTODOS}

\section{CONHECENDO À ESCOLA PARCEIRA}

A intervenção se deu a partir da oficina "Feira de Santana: memórias, imagens e história", na escola parceira, que faz parte da rede estadual de ensino e está localizada num bairro próximo ao centro da cidade de Feira de Santana, ela atende o fundamental II $\left(6^{\circ}\right.$ ao $9^{\circ}$ ano) e ao ensino médio, deste modo, o público alvo foram o $1^{\circ}$ ano do ensino médio. A oficina foi desenvolvida em conjunto com duas outras pesquisas: “Arte-educação no ensino do lugar 
em Feira de Santana: olhares e possibilidades da cidade educativa (técnica do Draw my life)" e "Imagens e imaginário da cidade de Feira de Santana: a produção do lugar a partir de publicações feirenses", assim, as atividades estavam relacionadas com a história de Feira de Santana, cartografias alternativas e a técnica do Draw my life.

\section{ESCOLHA DAS OBRAS DE ARTES PARA EXPOSIÇÃO}

Conforme consta no plano de trabalho, a princípio seriam apresentadas apenas duas obras de arte: Void de Marcelo Moscheta (2010) e Two Bostons de Nikki Rosato (2009), no entanto, no decorrer do planejamento desta intervenção, decidimos incorporar a coletânea de obras de arte, da coleção Santander Brasil, intitulada: A vastidão dos mapas - arte contemporânea em diálogo com mapas. A partir disso, selecionamos para expor na turma do $1^{\circ}$ ano ensino médio, as obras (Ocupa Corpo de Gal Oppido (2014); Diáspora de Chang Chi Chai (2005); Israel de Alex Flemming (2001); Europe de Fernando Zarif (1989); e SKY de Cristina Barroso (1998).

\section{“FEIRA DE SANTANA: MEMÓRIAS, IMAGENS E HISTÓRIA” (OFICINA)}

Inicialmente, foram entregues os questionários diagnósticos para a turma, em seguida iniciamos a contextualização sobre Feira de Santana, trazendo a discussão do porque é conhecida por "Feira dos Olhos d'água", trouxemos também a importância das feiras para esta cidade e como elas ajudaram no desenvolvimento do comércio e fortalecimento da cultura local. Na segunda etapa, começamos solicitando aos alunos que olhassem com atenção as imagens expostas na sala, e a partir disso, fizemos dois questionamentos: o primeiro, o que estavam vendo? E o segundo, se aquelas imagens tinham alguma relação com o conteúdo de geografia e cartografia? Para a primeira pergunta, eles responderam que se tratavam de diversas obras de artes e algumas tinham até presença de mapas, mapa-múndi "pegando fogo", mulher, mapa do céu, e etc. Já, em relação à última pergunta, os mesmos disseram que jamais imaginariam que obras de arte poderiam ser relacionadas com mapas e assim representar outras coisas, ou seja, "os mapas não serviam apenas para localização como foi aprendido durante as aulas e os livros didáticos de geografia".

Após, os questionamentos, iniciamos a apresentação no power point com vários tipos de mapas (do mapa mais antigo; o mapa encontrado no livro didático; até o produzido na plataforma de Sistemas de Informações Geográficas), em paralelo a isto, retornarmos as obras de artes, só que agora trazendo as explicações dos artistas para cada uma delas, e novamente os alunos ficaram impressionados ao descobrirem o significado dado pelos artistas ao terem se apropriado dos mapas para representar seus sentimentos. Finalizando esta etapa, solicitamos aos alunos que pensassem durante a outra apresentação, como eles queriam se expressar através dos mapas e da arte, pois colocariam em prática na última etapa da oficina. A terceira etapa foi dedicada à técnica Draw my life, que consiste em fazer desenhos para contar história da própria vida. A última etapa da oficina, foi destinada para a formação de dois grupos para produção dos mapas e histórias.

\section{DISCUSSÃO E RESULTADOS}

\section{ANÁLISE DO QUESTIONÁRIO DIAGNÓSTICO E AVALIATIVO}

O questionário diagnóstico era composto por 10 questões relacionadas a arte, educação, mapas e cartografia, porém só foram analisadas as específicas para minha pesquisa. Os alunos apresentavam uma faixa etária entre 14 e 18 anos de idade, a maioria nasceu em Feira de Santana e apenas sete em outros municípios (Salvador, Castro Alves, Serrinha, Wenceslau Guimarães e Camaçari), deste modo, quase todos residem em bairros periféricos próximo à escola, com exceção da aluna de Tanquinho. Quando questionados sobre o que entendem por 
mapas, as respostas desses alunos estavam sempre associadas a representação do espaço geográfico, a algo que auxilie na localização dentro deste espaço, um objeto (GPS, celular e etc), ou, uma ilustração do mundo que nos mostra os continentes com suas localizações e coordenadas. Em relação a cartografia, eles responderam que é o estudo/ciência dos mapas, elaboração de mapas, cartas, entre outros, e sobretudo, a cartografia tem a função de realizar cálculos de escalas e coordenadas. Para a maioria dos alunos, a arte tem um significado, pois é através dela que o mundo ganha força, cores, emoções e sentimentos, então, sem a arte seria impossível viver. Ao serem questionados, se dava para aprender conteúdos geográficos através da arte, eles responderam que sim, pois onde a arte está tudo ficar melhor e o nível de compreensão aumenta.

Já, o avaliativo, eles responderam que gostaram da oficina, pois nenhum classificou como ruim, seis classificaram como boa, sete como ótima e 10 alunos a classificaram como excelente. Questionados se "Feira de Santana: memórias, imagens e história" contribuiu para ampliar seus conhecimentos sobre Feira de Santana enquanto lugar, 14 alunos responderam sim e justificaram que através desta oficina conseguiram tirar dúvidas sobre Feira de Santana e apresentação de informações, mapas e coisas relacionado a esta cidade que até então eram desconhecidas, e um aluno disse que não o chamou atenção, sem justificar o motivo. Sobre o tema tratado na oficina (cartografia alternativas e arte-educação), nenhum aluno achou ruim, sete acharam boa, um ótima e 14 alunos classificaram como excelente. Em relação ao material produzido por eles, todos classificaram como excelente.

\section{ANÁLISE DAS PRODUÇÕES DOS ALUNOS}

As cartografias alternativas têm a função de proporcionar aos alunos um novo sentido de mapeamento e representação, através dos sentimentos, emoções, vivências e o que é experienciado por eles. Com isso, apresentaremos nos mosaicos (01 e 02) o que esses alunos conseguiram expressar no papel e em seguida a discussão de Girardi e Seemann em cima disso.

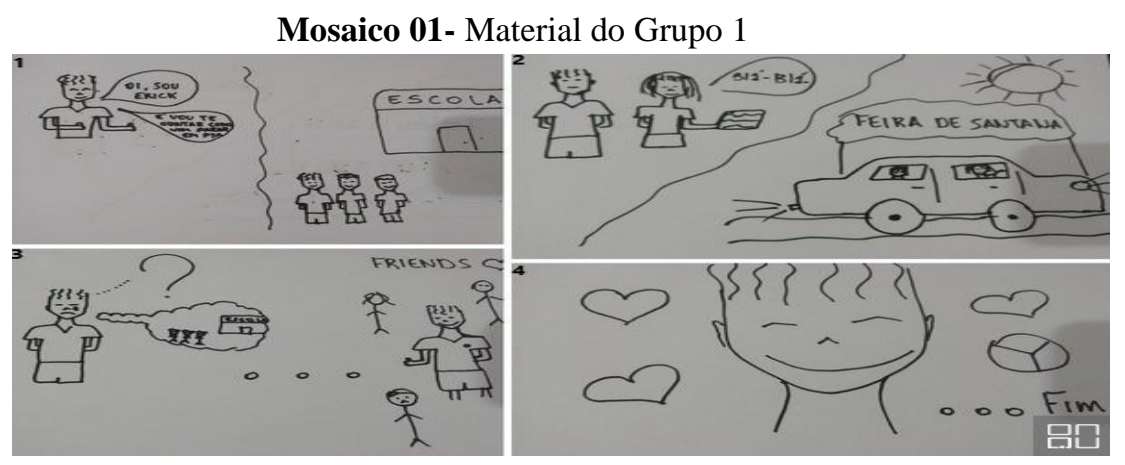

Fonte: Alunos, $1^{\circ}$ ano do ensino médio.

Este grupo através dos desenhos, contou a história de um garoto chamado Erick que explica como chegou em Feira de Santana, segundo a sequência, ele precisou largar a antiga escola e os velhos amigos para acompanhar os pais que estavam de mudança para Feira de Santana. Percebe-se, que o grupo 1 contou uma história focada mais na experiência individual de Erick, personagem criada por eles e dentro dela colocaram sentimentos, emoções, referências e traçam percursos para a mesma, sendo assim, o conceito de Seemann (2012) aponta que: "O mapa vai ao encontro das biografias humanas, porque contêm referências às vidas e práticas sociais das pessoas que estimulam a sua memória." Ou seja, o mapa se faz presente mesmo que não tenha sido mapeado e representado no papel. 




Fonte: Alunos, $1^{\circ}$ ano do ensino médio.

O segundo grupo, reproduziu o mapa (anel de contorno) de Feira de Santana que dava destaque para o bairro Caseb para contar a história elaborada por eles. A história começa, quando um bebê chamado Fernando foi abandonado nas ruas do Caseb pelos pais biológicos, porém Fernando é adotado por uma família que reside neste bairro. Aqui, o grupo representou em dois momentos: o primeiro ao tentar mostrar a localização do centro da cidade, e o segundo quando transformou o ditado "conhecer na palma das mãos" em desenho. Deste modo, Seemann (2012) afirma que: "o mapa é um paradoxo, porque, fisicamente, são meras marcas numa folha de papel, mas visualmente traz à mente um mundo multidimensional que contêm objetos e até emoções que não são diretamente percebíveis no papel."

Portanto, através dos mosaicos, observamos que os alunos conseguiram perceber os mapas como algo além da representação formal da cartografia tradicional, eles começaram a perceber que outras representações são possíveis, tanto que o (grupo 2) relacionou o ditado "conhecer na palma da mãos" na imagem 4 do (mosaico 2) mostrando que o personagem conhece aquele local como conhece a sua própria mão.

\section{CONCLUSÃO}

Destaca-se assim, a utilização das cartografias alternativas como o instrumento pedagógico nesta pesquisa de iniciação cientifica, auxiliou na discussão dos sentidos dados ao lugar através das representações dos mapas dos cartógrafos, artistas e dos alunos do ensino médio da escola parceira. Foram identificados nos desenhos, sentimentos, emoções e relações de vivência. E o mais importante de tudo, esses alunos deixaram de enxergar o mapa apenas como instrumento de localização, passando a considerar os mapas como algo que pode ir além de representar e expressar até mesmo nossos sentimentos.

\section{REFERÊNCIAS}

FARIAS, Agnaldo. A vastidão dos mapas - arte contemporânea em diálogo com mapas da coleção Santander Brasil, 2018.

GIRARDI, G. Cartografias Alternativas no Âmbito da Educação Geográfica. Revista Geográfica de América Central Número Especial EGAL, 2011- Costa Rica.

SEEMANN, J. Tradições Humanistas na Cartografia e a Poética dos Mapas. In: MARANDOLA JR, E.; OLZER, W. e OLIVEIRA, L.(org.) Qual o Espaço do Lugar? Geografia, Epistemologia, Fenomenologia. Ed. Perspectiva. São Paulo. 2012. 